\title{
GERMINAÇÃO DO BANCO DE SEMENTES DE ESPÉCIES NATIVAS SOB DOSSEL DE ESPÉCIES EXÓTICAS ${ }^{1}$
}

Flávia Maria da Silva Carmo², Lucas Marinho Poeiras³, Andrea Brandão Gonçalves ${ }^{3}$, Sabrina Marinho de Mello ${ }^{3}$, João Augusto Alves Meira Neto ${ }^{4}$, Eduardo Euclydes de Lima e Borges ${ }^{5}$ e Alexandre

Francisco da Silva ${ }^{6}$

\begin{abstract}
RESUMO - As sementes no solo desempenham o importante papel de promover a regeneração da vegetação e a conservação da biodiversidade local, mas, a despeito dessa importância, estão sujeitas a fatores bióticos e abióticos que podem inibir sua germinação, entre eles efeitos alelopáticos desencadeados pelas plantas que estão presentes no ambiente do solo. Neste trabalho foi testada a hipótese de que a germinação das sementes presentes no banco do solo sob vegetação de Floresta Estacional Semidecidual (FES) é inibida sob o dossel de espécies arbóreas exóticas. Foram coletadas 50 amostras simples de 0,25 x 0,25 x 0,05 m do solo em um fragmento de FES, que foram homogeneizadas, constituindo amostra composta. Desta, foram retiradas amostras que foram submetidas a quatro tratamentos: depositadas em casa de vegetação (SMN-CV); devolvidas ao fragmento de mata (SMN-MN); depositadas sob dossel homogêneo de Pinus elliottii (SMN-P); e alocadas sob plantio homogêneo de Eucalyptus sp. (SMN-E). Foram coletadas, também, amostras de solo sob dossel de P. elliotti (SP-CV) e de Eucalyptus sp. (SE-CV), que foram transferidas para casa de vegetação. A cada 15 dias, o número de plantas foi contado em cada amostra e as plantas obtidas, identificadas quando possível. Foram obtidas, ao todo, 515 plantas de 15 famílias botânicas, 21 gêneros e 13 morfoespécies. A análise de variância dos dados e a comparação das médias pelo teste de Tukey-Kramer a 0,01\% evidenciaram que não existem diferenças estatisticamente significativas entre o número de plantas obtidas em cada local. Esses resultados indicam que a baixa densidade e diversidade de plantas frequentemente verificadas no subosque de P. elliotti e Eucalyptus sp. não estão diretamente relacionadas com efeitos supressores promovidos pela presença dessas espécies, suportando dados recentes da literatura que apontam os plantios florestais de espécies exóticas como possíveis áreas de conservação da biodiversidade, em oposição à alcunha de "desertos verdes" que lhe são atribuídos.
\end{abstract}

Palavras-chave: Banco de sementes, Regeneração natural e Florestas plantadas.

\section{SEEDBED GERMINATION OF NATIVE SPECIES UNDER CANOPY OF EXOTIC SPECIES}

\begin{abstract}
The seeds in the soil play an important role in promoting the plant regeneration and acts on the local biodiversity conservation, but despite their importance, they are subject to biotic and abiotic factors that may inhibit their germination, including allelopathic effects triggered by the plants that are present in the soil environment. In this study we tested the hypothesis that the germination of seeds of seedbeds from
\end{abstract}

\footnotetext{
${ }^{1}$ Recebido em 17.11.2008 e aceito para publicação em 28.05.2012

${ }^{2}$ Universidade Federal de Viçosa, Centro de Ciências Biológicas e da Saúde, Departamento de Biologia Geral. E-mail: $<$ fmcarmoufv@gmail.com>.

${ }^{3}$ Universidade Federal de Viçosa, Centro de Ciências Biológicas e da Saúde, Departamento de Biologia Vegetal. E-mail: <poeiramar@hotmail.com>,<andrea_vix@yahoo.com.br>e < sabrinammello@hotmail.com>.

${ }^{4}$ Universidade Federal de Viçosa, Centro de Ciências Biológicas e da Saúde, Departamento de Biologia Vegetal. E-mail: $<$ j.meira@ufv.br >

${ }^{5}$ Universidade Federal de Viçosa, Centro de Ciências Agrárias, Departamento de Engenharia Florestal. E-mail: <elborges@ ufv.br>.

${ }^{6}$ In memorian.
} 
Semidecidual Seasonal Forest (SSF) is inhibited under the canopy of exotic trees. Fifty (50) single samples of soil were collected $(0.25 \times 0.25 \times 0.05 \mathrm{~m})$ in a fragment of $S S F$; the samples were homogenized and from that new samples were taken and submitted to four (4) treatments: 10 samples were deposited in the greenhouse $(S M N-C V)$; other 10 were returned to the forest fragment understory $(S M N-M N)$; 10 were deposited on the soil under homogeneous canopy of Pinus elliottii ( $S M N-P)$ and the last 10 samples were allocated under homogeneous plantation of Eucalyptus sp (SMN-E). We also collected samples of soil under the canopies of P. elliottii ( $S P-C V)$ and Eucalyptus sp.(SE-CV) that were transferred to a greenhouse. The number of seedlings was counted at intervals of 15 days in each seedbed sample and the plants obtained were identified when possible. We obtained 515 plants from 15 botanical families, 21 genera and 13 morphospecies. The analysis of variance and comparison of means by Tukey-Kramer $0.01 \%$ showed no statistical differences between the treatements. Outcomes indicate that the low density and diversity of plants in P. elliottii and Eucalyptus sp understory are not directly corelated to suppressive effects promoted by the presence of these species, supporting recent data from literature that stands out the forest plantations of exotic species as possible areas for biodiversity conservation, in opposition to the designation of "green deserts" that are assigned to them.

Keywords: Seed bank, Seedbed Plant natural regeneration and Planted forests.

\section{INTRODUÇÃO}

O banco de sementes, isto é, a reserva de sementes viáveis e não germinadas em determinado hábitat, é constituído por sementes produzidas localmente e por aquelas transportadas por zoocoria ou anemocoria, sendo de suma importância para a dinâmica e restabelecimento das comunidades vegetais principalmente após distúrbios - e para a manutenção da diversidade das espécies (GROMBONE-GUARATINI; RODRIGUES, 2002). A permanência e sobrevivência das sementes nas reservas do solo dependem de fatores bióticos, como a atividade de animais granívoros; de fatores abióticos, como a ocorrência de fogo, intempéries climáticas; e da presença de fatores inibitórios, incluindo alelopatia (THOMPSON; GRIME, 1979; WALCK et al., 1996; BASKIN; BASKIN, 2001; MALLIK, 2008).

Alelopatia é caracterizada pela produção e liberação para o meio de substâncias de metabolismo secundário que atuam sobre outros organismos do meio (RICE, 1984; WALLER, 1996). Entre as plantas, esses compostos aleloquímicos podem impedir a germinação das sementes ou o estabelecimento dos indivíduos (ALMEIDA, 1988; BORGES et al., 1993; DURIGAN; ALMEIDA, 1993), o que pode determinar mudanças na composição da vegetação e na diversidade local, influenciando também o padrão de distribuição das espécies (RICE, 1984; ALSAADAWI; ALRUBEAA, 1985; GRAKHOV et al., 1993).

A ocorrência mais intensa de efeitos alelopáticos negativos são esperados entre organismos que não têm histórias evolutivas comuns. Esses efeitos são especialmente observados entre espécies exóticas introduzidas em novos ambientes onde as plantas locais, por não apresentarem estratégias adaptativas selecionadas para lidar com os aleloquímicos exsudados/liberados no meio pelas plantas estranhas, perecem ou têm seu fitness diminuído. A isso Callaway e Ridenour (2004) chamaram de "hipótese das novas armas".

No Brasil, algumas espécies arbóreas exóticas apresentam status de invasoras, como Pinus elliottii Engelm., Pinus taeda L., Casuarina equisetifolia L., Melia azedarach L. (cinamomo), Tecoma stans (L.) Juss. ex Kunth (amarelinho), Hovenia dulcis Thunb. (uva-do-japão), Acacia mangium Willd., Eriobotrya japonica (Thunb.) Lindl. (nêspera), Ligustrum japonicum Thunb. (alfeneiro), Dodonaea viscosa (L.) Jacq., Azadirachta indica A. Juss. (neem), Leucaena leucocephala (Lam.) de Wit., muitas delas sendo também reportadas como alelopáticas (PARROTTA et al., 1997; ZILLER, 2001; PIRES et al., 2001; GISP, 2005; LUZ et al., 2010; SARTOR et al., 2009; RICKLI et al., 2011). Mas, apesar disso, algumas delas são utilizadas em plantios homogêneos para fins comerciais, o que tem sido considerado prática danosa ao ambiente e à biodiversidade, levando as áreas de monocultivo a serem chamadas de "desertos verdes" (CARDOSO; PIRES, 2009). Essa denominação se deve, principalmente, ao fato de que a presença de estrato regenerante de plantas nativas em sub-bosques de monocultivos é rara quando comparada com a situação nos sub-bosques das florestas nativas, o que leva a razoável consideração

Revista Árvore, Viçosa-MG, v.36, n.4, p.583-591, 2012 
de que há inibição da germinação das sementes e desenvolvimento das plantas sob tais circunstâncias, possivelmente por alelopatia.

Considerando o exposto, o objetivo deste trabalho foi testar a hipótese de que a germinação das sementes presentes no banco de sementes do solo sob Floresta Estacional Semidecídual é inibida quando se encontram sob o dossel de espécies arbóreas exóticas.

\section{MATERIAL E MÉTODOS}

\section{1. Área de estudo}

As coletas do banco de sementes ocorreram no campus da Universidade Federal de Viçosa (UFV), em Viçosa, MG (20³5'S e 42 $45^{\circ}$ ' W), em fragmento florestal conhecido como "Mata da Biologia", que possui aproximadamente 75 ha. As amostras do banco de sementes foram coletadas em uma parcela permanente de 1 ha dividida em 100 subparcelas contíguas de 10 x $10 \mathrm{~m}$, localizadas em uma encosta com elevação entre de $725 \mathrm{~m}$ e $745 \mathrm{~m}$ de altitude, declividade de aproximadamente $45^{\circ}$ e exposição solar oeste-sudoeste, cuja vegetação local se encontrava em regeneração natural há cerca de 76 anos (LOPES et al., 2002; PAULA et al., 2002; GASPARINI JÚNIOR, 2004).

De acordo com Veloso et al. (1991), a vegetação predominante dessa região é classificada como Floresta Estacional Semidecidual Montana, caracterizada pela mistura de espécies caducifólias e perenifólias. Nos topos e encostas há a predominância de solos do tipo Latossolo Vermelho-Amarelo, enquanto nos terraços predomina o Argissolo Vermelho-Amarelo (SILVA et al., 2000). O clima regional é do tipo $\mathrm{Cw}_{\mathrm{b}}$, mesotérmico úmido com verões chuvosos e invernos secos, conforme a classificação de Köeppen (VIANELLO;ALVES, 1991). A precipitação anual média é de $1.341 \mathrm{~mm}$, com umidade relativa do ar anual média de $80 \%$; a temperatura do ar média durante o ano é de $19^{\circ} \mathrm{C}$, com média mínima de $14^{\circ} \mathrm{C}$ e média máxima de $21,6^{\circ} \mathrm{C}$ (CASTRO et al.,1973).

Os dados mensais médios de clima - temperaturas máxima e mínima, precipitação, evaporação e insolação - nos anos de 2005 a 2007 foram obtidos na Estação Meteorológica do Departamento de Engenharia Agrícola da UFV e são apresentados na Figura 2. No intervalo de tempo compreendido entre a primeira coleta do banco de sementes do solo e a última houve períodos de seca acentuados entre maio e agosto de 2006 e maio e agosto de 2007 e um pico de precipitação mais elevada do que os registrados no período entre dezembro de 2006 e janeiro de 2007. As temperaturas médias mensais oscilaram entre $10^{\circ} \mathrm{C}$ e $30^{\circ} \mathrm{C}$, sem apresentar distúrbios em relação aos registros anteriores.

\subsection{Coleta e análise de dados}

As amostras do solo foram coletadas em 50 das 100 subparcelas, de forma que fossem intercaladas entre si por uma parcela onde não houve coleta. Para a amostragem foi utilizado um gabarito de madeira com dimensões de 0,25 x 0,25 m de frente e 0,05 m de profundidade, considerando-se a camada de serapilheira, que também foi coletada,

As amostras simples foram homogeneizadas, constituindo uma amostra composta, que foi, então, separada em 50 amostras de pesos semelhantes, trabalhadas da seguinte forma: 10 amostras foram depositadas em casa de vegetação (SMN-CV), 10 foram devolvidas às mesmas subparcelas de onde foram retiradas (SMN-MN), 10 foram depositadas aleatoriamente sob o dossel de um plantio homogêneo

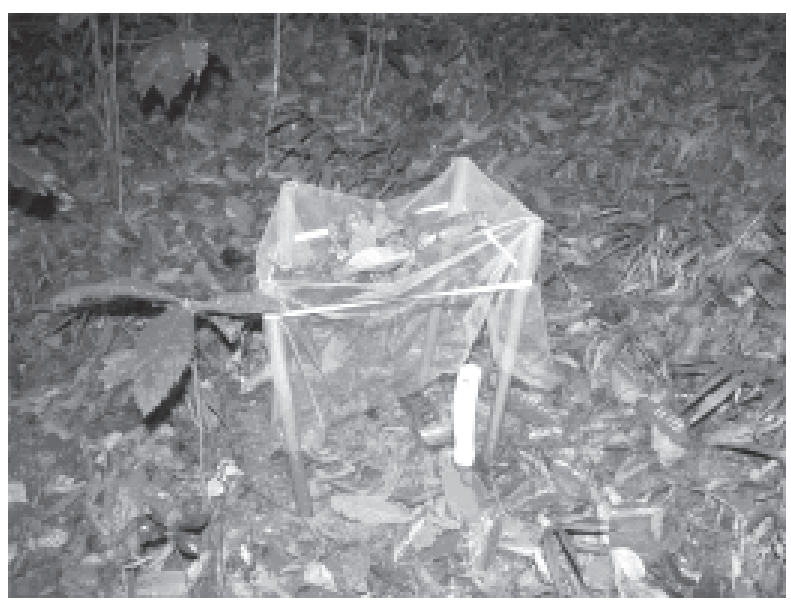

Figura 1 - Amostra do banco de sementes do solo retornada ao substrato sob dossel de Floresta Estacional Semidecidual Montana e guarnecida por um capuz de filó branco para evitar a entrada de novos propágulos no local.

Figure 1 - Soil seed bank sample returned to Semidecidual Seasonal Forest (SSF) floor and protected by a hood of white tulle to prevent the entry of new propagules on the site.

Revista Árvore, Viçosa-MG, v.36, n.4, p.583-591, 2012 
de Pinus elliottii (SMN-P) e 10 amostras foram alocadas aleatoriamente sob plantio homogêneo de Eucalyptus sp. (SMN-E). Na casa de vegetação, as amostras foram mantidas em bandejas de alumínio $(25 \mathrm{~cm}$ x $35 \mathrm{~cm} \mathrm{x}$ $5 \mathrm{~cm}$ ) com fundo perfurado e regadas, periodicamente, com água de torneira. Já nas áreas de mata e nos plantios, foi retirada uma fração superficial de terra $(1-2 \mathrm{~cm})$ junto com a serapilheira, e as amostras foram depositadas diretamente na superfície do solo e, então, guarnecidas por um "capuz" de filó branco (Figura 1), para evitar a entrada de novos propágulos no local.

Utilizando os mesmos procedimentos descritos anteriormente, foram coletadas 10 amostras de solo sob dossel de Pinus elliotti e 10 de solo sob dossel de Eucalyptus sp. Essas amostras foram homogeneizadas, acondicionadas em bandejas de alumínio e depositadas na casa de vegetação junto com as demais, sendo denominadas SP-CV e SE-CV, respectivamente.

Esses procedimentos foram efetuados quatro vezes, sendo a primeira coleta realizada em setembro de 2005 e a quarta, em setembro de 2006. O intervalo de tempo entre elas foi de aproximadamente três meses, de forma que em cada estação do ano foi realizada uma coleta do banco de sementes na mata e nos plantios. As amostras dos bancos de sementes tanto no campo quanto na casa de vegetação foram avaliadas quinzenalmente, contando-se as plantas até que não se obtivesse mais germinação em um período superior a 60 dias. Portanto, a coleta de dados foi finalizada em fevereiro de 2007.

As plantas obtidas em cada contagem foram transferidas para sacos plásticos para crescimento de mudas e mantidas sob tela de náilon tipo sombrite $70 \%$ para posterior reconhecimento dos indivíduos, o que foi feito pelo menos em nível de família.

O número de plantas obtidas em cada local foi considerado como variável resposta, sendo os resultados analisados com o uso da análise de variância simples (Anova one-way), com contraste de médias pelo teste de Tukey-Kramer a 0,01\%.

\section{RESULTADOS}

Foram amostrados uma área de $3,125 \mathrm{~m}^{2} \mathrm{e}$ um volume de $1,5625 \mathrm{~m}^{3}$ de solo, obtendo-se 515 plantas. Entre estas foram reconhecidos 14 espécies e seis gêneros,

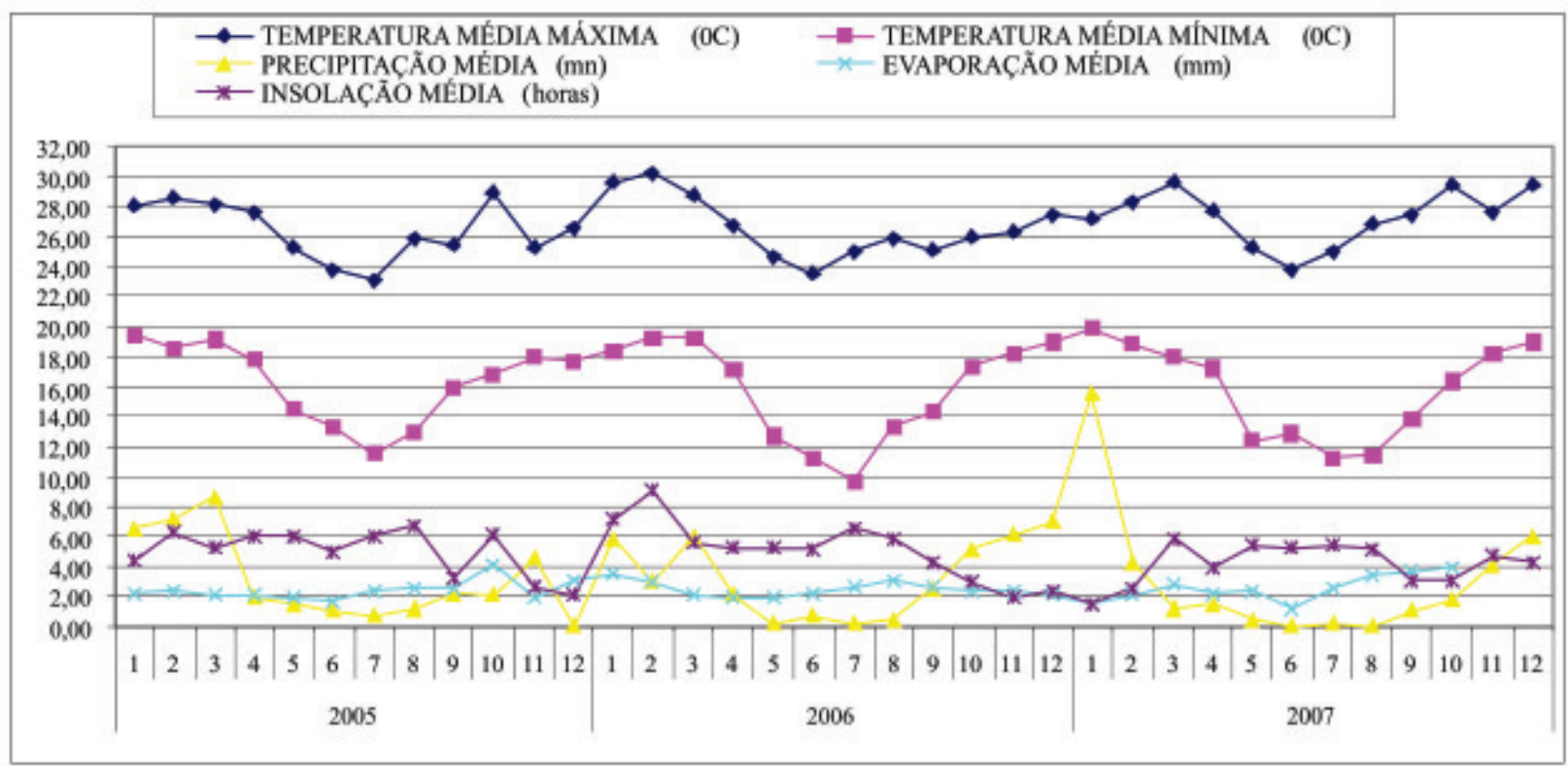

Figura 2 - Médias mensais de temperatura máxima, temperatura mínima, precipitação, evaporação e insolação em Viçosa, MG, entre os anos de 2005 e 2007.

Figure 2 - Monthly averages of maximum temperature, minimum temperature, precipitation, evaporation and insolation at Viçosa, MG, between the years 2005 and 2007.

Revista Árvore, Viçosa-MG, v.36, n.4, p.583-591, 2012 
pertencentes a 15 famílias botânicas. Também foram separadas 13 morfoespécies, totalizando 33 entidades taxonômicas. A maioria das plantas foi obtida na primeira contagem do banco de sementes do solo. A partir da identificação das plantas, foi elaborada uma lista florística, incluindo aqueles indivíduos identificados em nível de morfoespécie (Tabela 1).

A análise dos dados indicou que não existem diferenças estatisticamente significativas no número de plantas obtidas em cada tratamento dado ao solo amostrado na mata $\left(\mathrm{F}_{(5,18)}=0,4033 ; \mathrm{P}>\mathrm{F} 0,8402\right)$ e que

Tabela 1 - Lista florística das plantas germinadas nas amostras do solo de Floresta Estacional Semidecidual em Viçosa, MG.

Table 1 -Floristic list of plants germinated in samples of soil from Semidecidual Seasonal Forest in Viçosa, $M G$

\begin{tabular}{|c|c|}
\hline Espécie & Família \\
\hline Amaranthus viridis $\mathrm{L}$. & Amaranthaceae \\
\hline Casearia ulmifolia Vahl ex Vent & Flacourtiaceae \\
\hline Cecropia glaziovii Sneth1. & Urticaceae \\
\hline Cecropia hololeuca Miq. & Cecropiaceae \\
\hline \multicolumn{2}{|l|}{ Conyza primulifolia (Lam.) } \\
\hline Cuatrec. \& Lourteig & Asteraceae \\
\hline Impatiens walleriana Hook. f. & Balsaminaceae \\
\hline Richardia scabra L. & Rubiaceae \\
\hline Siparuna guianensis Aubl. & Monimiaceae \\
\hline Solanum americanum Mill. & Solanaceae \\
\hline Sorocea bomblandii. Boer & Moraceae \\
\hline Tibouchina granulosa (Desr.) Cogn. & Melastomataceae \\
\hline Trema micrantha (L.) Blume & Cannabaceae \\
\hline Vernonia diffusa Less. & Asteraceae \\
\hline Vernonia polyanthes (Spreng.) Less. & Asteraceae \\
\hline Bidens sp. & Asteraceae \\
\hline Brachiaria sp. & Poaceae \\
\hline Commelina sp. & Commelinaceae \\
\hline Miconia sp. & Melastomataceae \\
\hline Piptocarpha sp. & Asteraceae \\
\hline Morfoespécie 1 & - \\
\hline Morfoespécie 2 & - \\
\hline Morfoespécie 3 & - \\
\hline Morfoespécie 4 & - \\
\hline Morfoespécie 5 & Rubiaceae \\
\hline Morfoespécie 6 & - \\
\hline Morfoespécie 7 & - \\
\hline Morfoespécie 8 & - \\
\hline Morfoespécie 9 & - \\
\hline Morfoespécie 10 & - \\
\hline Morfoespécie 11 & Melastomataceae \\
\hline Morfoespécie 12 & \\
\hline Morfoespécie 13 & \\
\hline
\end{tabular}

a transferência das amostras do banco de sementes para ambientes sob dossel de espécies exóticas não inibiu significativamente a germinação das sementes de espécies arbóreas nativas presentes nesse solo.

Foi obtido maior número de plantas nas amostras de solo na casa de vegetação. Das que foram levadas para o campo, as que apresentaram menor número de sementes germinadas foram aquelas depositadas sob o dossel da FES (Figura 3). Em todos os tratamentos foi verificada grande variação no padrão de germinação das sementes, fato esse que contribuiu para que não fossem evidenciadas diferenças estatisticamente significativas entre os dados obtidos nos tratamentos.

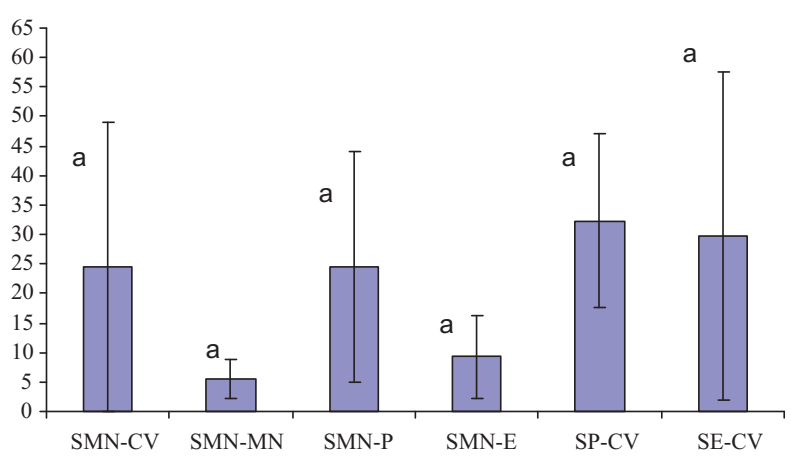

Figura 3 - Número de plantas obtidas nas amostras do solo sob Floresta Estacional Semidecidual (Mata Nativa - MN) em Viçosa, MG, em quatro coletas durante um ano. Em que: SMN-CV: solo de Mata Nativa depositadas em casa de vegetação; SMN-MN: solo da Mata Nativa depositadas sob solo de Mata Nativa; SMNP: solo da Mata Nativa depositadas sob dossel de Pinus elliottii; SMN-E: solo da Mata Nativa depositadas sob dossel de Eucalyptus sp.; SP-CV: solo do plantio homogêneo de Pinus elliottii depositadas em casa de vegetação; e SE-CV: solo do plantio homogêneo de Eucalyptus sp. depositadas em casa de vegetação.

Figure 3-Number of plants obtained in the samples of soil from Semidecidual Seasonal Forest (native forest) in Viçosa, MG, in four samples during one year. SMN-CV: soil from native forest deposited in a greenhouse; $S M N-M N$ : soil from native forest deposited under the native forest; $S M N-P$ : soil from native forest deposited under the canopy of Pinus elliottii; $S M N-E$ : soil from native forest deposited under the canopy of Eucalyptus sp.; SP-CV: soil from planting of Pinus elliottii deposited in greenhouse, and SE-CV: soil from planting of Eucalyptus sp. deposited in greenhouse.

Revista Árvore, Viçosa-MG, v.36, n.4, p.583-591, 2012

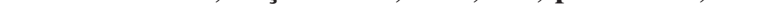

\section{Silf}




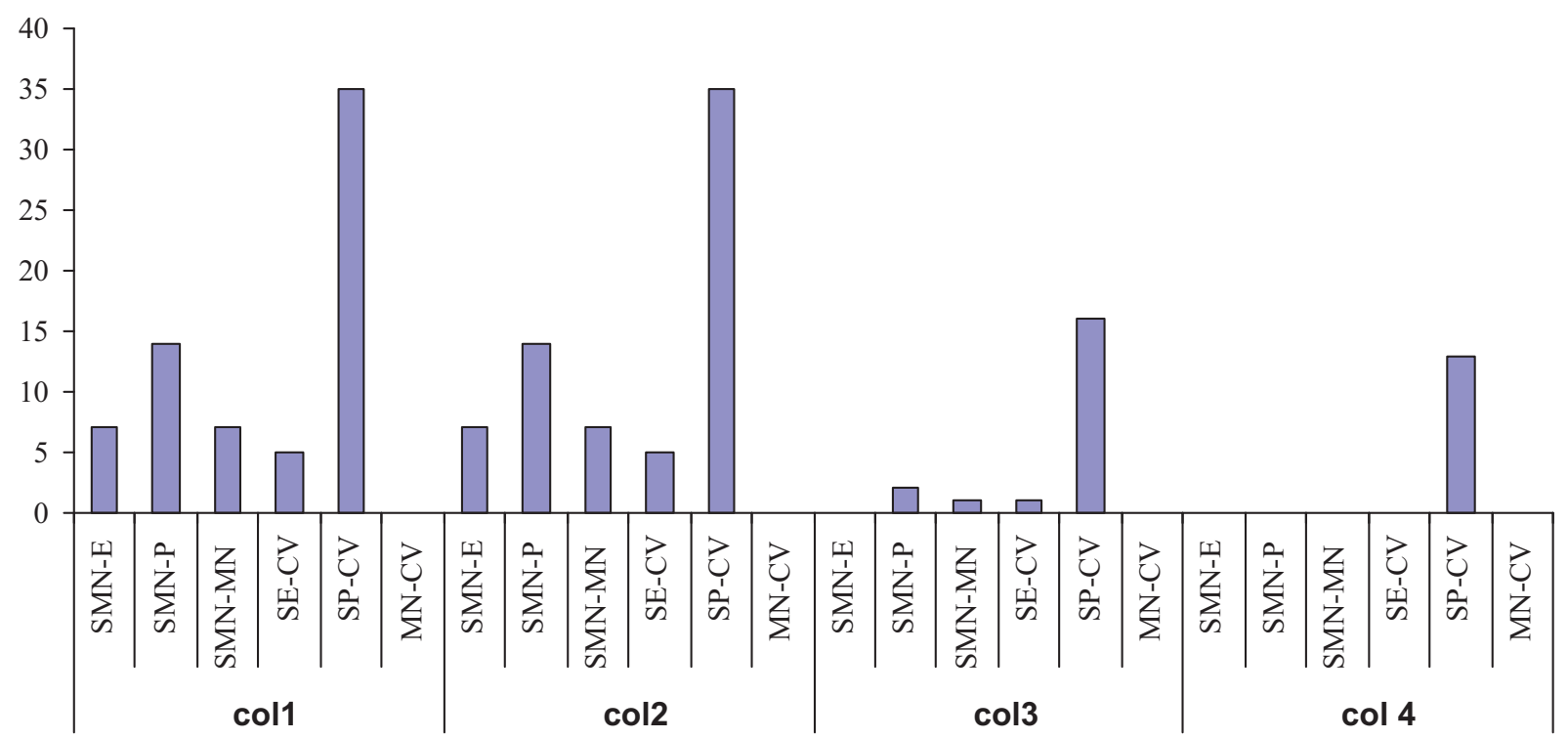

Figura 4 - Número de plantas germinadas nas amostras do solo de Floresta Estacional Semidecidal, entre setembro de 2005 e fevereiro de 2007. SMN-E: solo de mata nativa sob Eucalyptus sp.; SMN-P: solo de mata nativa sob Pinus elliotti; SMN-MN: solo de mata nativa sob mata nativa; SE-CV: solo de Eucalyptus sp. em casa de vegetação; SP-CV: solo de Pinus elliotti em casa de vegetação; MN-CV: solo de mata nativa em casa de vegetação; col1: primeira coleta ; col2: segunda coleta ; col3: terceira coleta e col4: quarta coleta.

Figure 4-Number of plants germinated in the samples of soil from Semidecidal Seasonal Forest (native forest), between September 2005 and February 2007. SNM-E: soil from native forest under Eucalyptus.; SMN-P: soil from native forest under Pinus elliotti; SMN-MN: soil from native forest under native forest, SE-CV: soil from Eucalyptus sp. planting in greenhouse; SP-CV: soil from Pinus elliottii planting in greenhouse, MN-CV: soil from native forest soil in greenhouse; coll: first sampling ; col2: second sampling; col3 : third sampling and col4: fourth sampling..

Comparativamente, obtiveram-se mais plantas sob dossel de Pinus elliotti, que foram mantidas em casa de vegetação. Também, foi observado que as duas primeiras coletas de solo, ou seja, aquelas realizadas em setembro e em janeiro, resultaram em número maior de plantas em todos os tratamentos em relação às duas últimas coletas, que foram realizadas em maio e em setembro. Aúltima amostragem, realizada em setembro de 2006, resultou em somente 13 plantas (Figura 4)

\section{DISCUSSÃO}

De acordo com os dados, foi rejeitada a hipótese de que a germinação das sementes presentes no banco de sementes do solo sob Floresta Estacional Semidecídual é inibida quando se encontra sob o dossel de espécies arbóreas exóticas.
A obtenção de plantas originadas do banco de sementes do solo de FES e germinadas sob dossel de Pinus elliotti e de Eucalyptus sp. implica que essas espécies nativas têm potencial para se estabelecer nesses locais, ao contrário do que sugere a baixa diversidade de espécies frequentemente observadas no sub-bosques de plantio homogêneo de espécies exóticas. Isso indica, portanto, que a potencial liberação de aleloquímicos pelas plantas exóticas no ambiente desses monocultivos não impediu a germinação de considerável porção das sementes que chegaram aos locais. Os dados aqui apresentados não permitem afirmar, porém, que efeitos alelopáticos negativos não tenham atuado, uma vez que as sementes que possam ter sofrido essa ação simplesmente não germinaram. No entanto, as que germinaram podem pertencer a espécies naturalmente resistentes, significando que podem ser potencialmente valiosas 
para a contenção de invasões de hábitats por espécies de Pinus e de Eucaliptus, como preconizaram Souza et al. (2009).

Estudos recentes caracterizando a regeneração natural de espécies arbustivas e arbóreas nativas no sub-bosque dos plantios florestais de espécies exóticas têm apontado que a esses sistemas estão associadas comunidades vegetais consideravelmente diversas, indicando que tais locais podem ser catalisadores da regeneração natural de muitas espécies nativas (LUGO, 1997; NERI et al., 2005; MODNA et al., 2010; VIANI et al., 2010; ARMANDO et al., 2011). Segundo alguns autores, a causa principal da baixa biodiversidade vegetal nos sub-bosques das florestas plantadas é a forma de manejo a que são submetidos. Carneiro e Rodrigues (2007) chamaram a atenção para o manejamento adequado, que permite que a regeneração natural transforme o status dessas áreas para ilhas de conservação local da biodiversidade em vez de "desertos verdes".

Embora não tenham sido detectadas diferenças estatisticamente significativas, o número total de plantas germinadas em cada tratamento das amostras do banco de sementes do solo sugere que as sementes deixadas sob dossel de P. Elliotti e de Eucalyptus sp. foram beneficiadas em relação àquelas retornadas à mata nativa. Esses dados são corroborados por estudos realizados na mesma parcela do fragmento da Mata da Biologia, que evidenciaram que as espécies arbóreas presentes no local são, em sua maioria, ecologicamente classificadas como secundárias iniciais e tardias, cujas sementes germinaram sob baixa intensidade de luz, semelhantemente às condições predominantes no pinhal (LOPES et al., 2002; PAULA et al., 2002; GASPARINI JUNIOR, 2004; CAMPOS et al., 2009). Ademais, Arévalo e Fernadez-Palacios (2005) reportaram que a proteção do solo e o sombreamento proporcionado pelas árvores em plantios de Pinus foram fatores determinantes para o estabelecimento de espécies nativas no seu subosque. Os resultados também podem ser parcialmente explicados pela ausência ou pela menor riqueza e densidade de predadores de sementes nos plantios em relação à mata nativa (DARIO et al., 2002), favorecendo a germinação de maior número de plantas nesses locais.

A metodologia adotada neste trabalho é nova e, portanto, também foi testada. Nesse sentido, algumas inadequações metodológicas podem ter contribuído para os resultados, entre elas a coleta e manuseio do solo, que foi revolvido e destorroado, perdendo sua estrutura e alterando sua granulometria. A perda de estrutura do solo resulta em dificuldade de absorção e retenção de água da chuva e da reserva do solo (PIRES, 2006), levando à dessecação de sementes que, por consequência, perdem a capacidade germinativa. Isso pode ter sido particularmente problemático para as amostras do banco de sementes transferidas para a mata, onde predomina a topografia declivosa. Essa hipótese é corroborada pelos dados de Camargos (2008), que obteve 528 plantas germinadas no banco de sementes do solo de 10 amostras de 40 x 25 x $5 \mathrm{~cm}$, coletadas no mesmo fragmento florestal, a poucos metros da área de coleta deste estudo, mas preservando-se a estrutura do solo. Camargos (2008) realizou uma única amostragem e, embora a área e o volume de solo coletado tenham sido menores, foi obtido semelhante número de plantas.

Assim, conclui-se que nas condições em que foi desenvolvido este trabalho não se observou influência negativa do dossel de Pinus elliotti e Eucaliptus sp. sobre o comportamento germinativo das sementes no banco do solo de FES. Também, não ficou claro se houve efeito alelopático seletivo na germinação das sementes presentes nas amostras de solo. É importante salientar que, por ter sido empregada uma nova metodologia para testar a hipótese proposta, há necessidade de outras investigações para confirmar a sua adequação para o tipo de trabalho realizado.

\section{AGRADECIMENTOS}

Os autores agradecem a FAPEMIG (Fundação de Amparo a Pesquisa do Estado de Minas Gerais) pelo suporte financeiro para o custeio do projeto e pelas bolsas de Iniciação Científica (Fapemig CRA732/04).

\section{REFERÊNCIAS}

ALMEIDA, F. S. Alelopatia e as plantas. Londrina: IAPAR, 1988. 60p. (Circular, 53)

ALSAADAWI, I. S.; ALRUBEAA, A. J.

Allelopathic effects of Citrus auratiumL. I. Vegetation patterning. Journal of Chemical Ecology, v.11, n.11, p.1515-24, 1985

ARÉVALO, J. R.; FENÁNDEZ-PALACIOS, J. M. Gradient analysis of exotic Pinus radiata plantations and potential restoration of natural vegetation in Tenerife, Canary Islands (Spain). Acta Oecologica, v.27, n.1, p.1-8, 2005. 
ARMANDO, D. M. S. et al. Colonização de espécies arbustivo-arbóreas em povoamento de Eucalyptus spp., Lavras, MG. Floresta e Ambiente, v. 18, n.4, p.376-389, 2011.

BASKIN, C. C.; BASKIN, J. M. Germination ecology of seeds in the persistent seed bank. In: BASKIN, C. C.; BASKIN, J. M. Seeds: ecology, biogeography and evolution. San Diego: Academic Press, 2001. p.133-164.

BORGES, E. E. L. et al. Avaliação de substâncias alelopáticas em vegetação de uma floresta secundária. I. Árvores. Revista Árvore, v.17, n.1, p.69-84, 1993.

CALLAWAY, R. M.; RIDENOUR, W. M. Novel weapons: invasive success and the evolution of increased competitive ability. Frontiers in Ecology and the Environment, v.2, n. 8, p.436-443, 2004

CAMARGOS, V. L. Impactos do fogo no estrato de regeneração e no banco de sementes do solo em um trecho de floresta estacional semidecidual. 2008. 61f. Tese (Doutorado em Botânica) - Universidade Federal de Viçosa, Viçosa, MG, 2008.

CAMPOS, E. P. et al. Chuva de sementes em Floresta Estacional Semidecidual em Viçosa, MG, Brasil. Acta Botanica Brasilica, v.23, n.2, p.451-458, 2009.

CARDOSO, R. S. B.; PIRES, L. V. Algumas considerações sobre a monocultura do eucalipto e suas implicações. In: SIMPÓSIO INTERNACIONAL DE REFORMA AGRÁRIA 4.; SIMPÓSIO NACIONAL DE GEOGRAFIA

AGRÁRIA, 5., Universidade Federal Fluminense, 2009. Disponível em: <http:// www.uff.br/vsinga/trabalhos/

Trabalhos\%20Completos/

Rafael\%20Said\%20Bhering\%20Cardoso.pdf>

CARNEIRO, P. H. M.; RODRIGUES, R. R. Management of monospecific commercial reforestations for the forest restoration of native species with high diversity. In: RODRIGUES, R. R. et al. High diversity forest restoration in degraded areas: methods and projects in Brazil. New York: Nova Science Publishers, 2007. p.129-144.
CASTRO, P. S. et al. Interceptação da chuva por mata natural secundária na região de Viçosa, MG. Revista Árvore, v.7, n.1, p.76-88, 1973.

DARIO, F. R.; VINCENZO, M. C. V.; ALMEIDA, A. F. Avifauna em fragmentos da Mata Atlântica. Ciência Rural, v.32, n.6, p.989-996, 2002.

DURIGAN, J. C.; ALMEIDA, F. S. Noções sobre a alelopatia. Jaboticabal: UNESP/FUNEP, 1993. 28p. (Boletim Técnico)

\section{GASPARINI JÚNIOR, A. J. Estrutura e dinâmica de um fragmento de floresta estacional semidecidual no Campus da Universidade Federal de Viçosa. 2004. 54f. Tese (Mestrado em Botânica) - Universidade Federal de Viçosa, Viçosa, MG, 2004.}

GISP. South America invaded: the growing danger of invasive alien species. Nairobi: The Global Invasive Species Programme, 2005. 80p

GRAKHOV, V. P.; KOSEKO, V. G. \& GOLOVKO, E. A. Modeling of allelopathic interactions in laboratory tests. Ukrayins Kyi Botanichnyi Zhurnal, v.50, n.1, p.86-93, 1993.

GROMBONE-GUARATINI, M. T.; RODRIGUES, R. R. Seed bank and seed rain in a seasonal semideciduous forest in south-eastern Brazil. Journal of Tropical Ecology, v.18, n.5, p.759-774, 2002.

LOPES, W. P. et al. Composição da flora arbórea de um trecho de floresta estacional no Jardim Botânico da Universidade Federal de Viçosa (face sudoeste), Viçosa, Minas Gerais. Revista Árvore, v.26, n.3, p.339-347, 2002.

LUGO, A. E. The apparent paradox of reestablishing species richness on degraded lands with tree monocultures. Forestry Ecology and Management, v.99, n.1, p.9-19, 1997.

LUZ, S. M. I. et al. Atividade alelopática de substâncias químicas isoladas da Acacia mangium e suas variações em função do $\mathrm{pH}$. Planta Daninha, v.28, n.3, p.479-487, 2010. 
MALLIK, A. U. Allelopathy in forested ecosystems. In: ZENG, R. S., MALLIK, A. U.; LUO, S. M. (Eds). Allelopathy in sustainable agriculture and forestry. New York: Springer, 2008. p.363-386.

MODNA, D.; DURIGAN, G.; VITAL, M. V. C. Pinus elliottii Engelm como facilitadora da regeneração natural da mata ciliar em região de Cerrado, Assis, SP, Brasil. Scientia

Forestalis, v.38, n.85, p.73-83, 2010.

NERI, A. V.; CAMPOS, E. P.; DUARTE, T. G. Regeneração de espécies nativas lenhosas sob plantio de Eucalyptus em área de Cerrado na Floresta Nacional de Paraopeba, MG, Brasil. Acta Botanica Brasilica, v.19, n.2, p.369376, 2005.

PARROTTA, J. A.; TURNBULL, J. W.; JONES, N. Catalyzing native forest regeneration on degraded tropical lands. Forest Ecology and Management, v. 99, n.1, p.1-7, 1997.

PAULA, A. et al. Alterações florísticas ocorridas num período de quatorze anos na vegetação arbórea de uma Floresta Estacional Semidecidual em Viçosa-MG. Revista Árvore, v.26, n.6, p.743-749, 2002.

PIRES, L. F. Tomografia computadorizada, atenuação de raios gama e análise micromorfológica na avaliação de alterações na estrutura e retenção de água pelo solo. 2006. 229 p. Tese (Doutorado em Energia na Agricultura e no Ambiente) - Universidade de São Paulo, Centro de Energia Nuclear na Agricultura, Piracicaba, 2006.

PIRES, N. M. et al. Atividade alelopática da Leucena sobre espécies de plantas daninhas Scientia Agricola, v.58, n.1, p.61-65, 2001.

RICE, E. L. Allelopathy. 2.ed. New York: Academic Press, 1984. 422 p.

RICKLI, H. C. Efeito alelopático de extrato aquoso de folhas de Azadirachta indica A. Juss. em alface, soja, milho, feijão e picão-preto, Semina: Ciências Agrárias, v.32, n.2, p.473-484, 2011.
SARTOR, L. R. et al. Alelopatia de acículas de Pinus taeda na germinação e no desenvolvimento de plântulas de Avena strigosa, Ciência Rural, v.39, n.6, P.1653-1659, 2009

SILVA, A. F.; FONTES, N. R. L.; LEITÃO FILHO, H. F. Composição florística e estrutura horizontal do estrato arbóreo de um trecho da mata da biologia da Universidade Federal de Viçosa. Revista Árvore, v.24, n.4, p.397-405, 2000.

SOUZA D. R.; MARTINS, M. L.; CARMO, F. M. $S$. A multiscale model for plant invasion through allelopathic Suppression. Biological Invasions, v. 12, n.6, p.1543-1555, 2010.

THOMPSON, K.; GRIME, J. P. Seasonal variation in the seed banks o herbaceus species in the contrasting habitats. Journal of Ecology, v.67, n.3, p.893-921, 1979.

VELOSO, H. P.; RANGEL FILHO, A. L. R.; LIMA, J. C. A. Classificação da vegetação brasileira, adaptada a um sistema universal. Rio de Janeiro: IBGE, 1991. 123p.

VIANELLO, R. L.; ALVES, A. R. Meteorologia básica e aplicações. Viçosa, MG:

Universidade Federal de Viçosa, 1991. 448p.

VIANI, R. A. G.; DURIGAN, G.; MELO, A. C. G. A regeneração natural sob plantios florestais: desertos verdes ou redutos de biodiversidade? Ciência Florestal, v. 20, n. 3, p. 533-552, 2010.

WALCK, J. L.; BASKIN, J. M. \& BASKIN, C. C. An ecologically and evolucionarily meaningful definition of persistent seed bank in Solidago. American Journal of Botany S6, p.78-79, 1996.

WALLER, G. R. Allelopathy: a science for the future. In: WORLD CONGRESS ON ALLELOPATHY, 1. , 1996, Cadiz. Proceedings... Cadiz: International Allelopathy Society, 1996. 278 p.

ZILLER, S. R. Plantas exóticas invasoras: a ameaça da contaminação biológica. Ciência Hoje, v.178, p.77-79, 2001. 
